\title{
Echocardiographic evaluation and medical management of mitral and tricuspid regurgitation in a spitz
}

\author{
Govindarajan Vijayakumar ${ }^{1}$, Ayyanampakkam Pandurangan Nambi ${ }^{1}$, Puzuthivakkam Subramaniam \\ Thirunavukkarasu ${ }^{2}$ and Sethupandian Prathaban ${ }^{3}$
}

\begin{abstract}
1. Centre of Advanced Faculty Training in Veterinary Clinical Medicine, Ethics and J urisprudence, Madras Veterinary College, Tamil Nadu Veterinary and Animal Sciences University, Chennai- 600 007, Tamil Nadu, India; 2. Professor and Head, Department of Clinics, Madras Veterinary College, Tamil Nadu Veterinary and Animal Sciences University, Chennai-7, India; 3. Dean, Veterinary College and Research Institute, Tirunelveli, Tamil Nadu Veterinary and Animal Sciences University, India

Corresponding author: Govindarajan Vijayakumar, email: drvijaymvc@gmail.com Received: 12-06-2012, Accepted: 23-07-2012, Published online: 27-12-2012
\end{abstract}

How to cite this article: Vijayakumar G, Nambi AP, Thirunavukkarasu PS and Prathaban S (2013) Echocardiographic evaluation and medical management of mitral and tricuspid regurgitation in a spitz , Vet World 6(3): 166-168, doi: 10.5455/ vetworld.2013.166-168

\section{I ntroduction}

Chronic valvular disease is the most important cause of heart disease in dogs. Acquired valvular insufficiency was usually secondary to degenerative valvular disease [1]. Although dogs can compensate for valvular insufficiency with time, decompensation and congestive heart failure may develop. Doppler examination plays a critical role in the assessment of dogs affected by valvular disease, providing information on ventricular size and function [2]. Enalapril is considered to be firstline adjunct to diuretic therapy when managing animals with heart failure [3]. This article describes clinico pathological changes and successful management of mitral and tricuspid regurgitation in a dog with enalapril and frusemide.

\section{Case history and observation}

A fifteen years old male spitz weighing about 8.2 $\mathrm{kg}$ was brought to Madras Veterinary College Teaching Hospital with history of cough, distension of abdomen and anorexia. The dog was dull, depressed, dehydrated with dry and pale pink mucous membrane, with normal temperature $\left(38.6^{\circ} \mathrm{C}\right)$, tachycardia, polypnoea, strong pulse and ascites. Auscultation revealed exaggerated lung sound and cardiac murmur (Grade V).

Haematological examination showed elevated haematocrit $(46 \%)$, normal haemoglobin $(10 \mathrm{mg} / \mathrm{dl})$, normal RBC count $\left(6.2 \times 10^{6} / \mathrm{cumm}\right)$ and mild leuko-

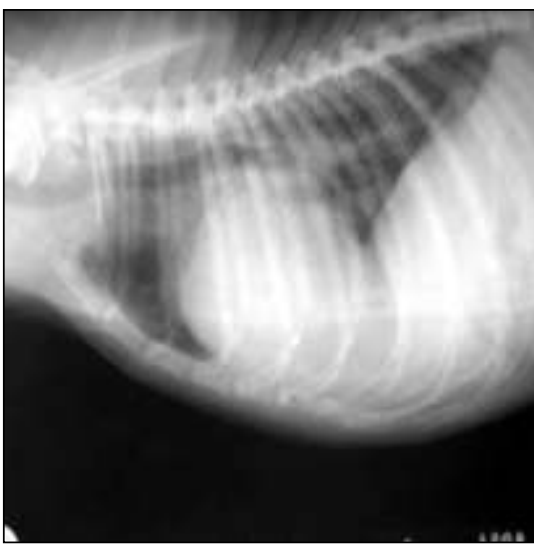

Fig-1a. Chest radiograph: lateral view, cardiomegally

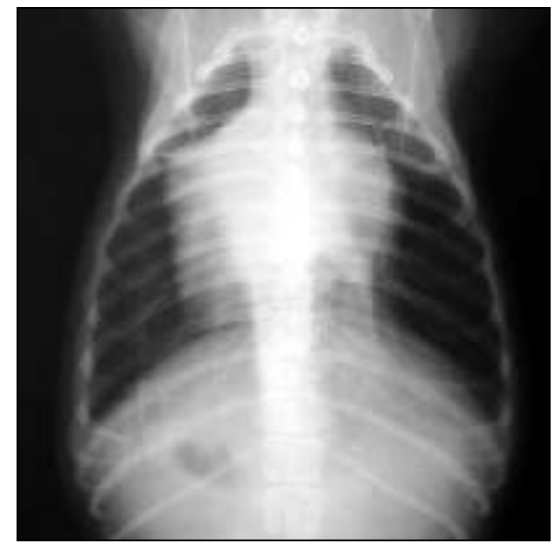

Fig-1b. Chest radiography, DV cardio-megally cytosis $\left(15.8 \times 10^{3} / \mathrm{cumm}\right)$. Electrocardiography revealed sinus rhythm and survey radiography (Fig $1 \mathrm{a} \& \mathrm{~b}$ ) showed cardiomegaly with VHS of 12.5. Echocardiography with colour Doppler showed mosaic pattern in the right and left atriums suggesting tricuspid and mitral regurgitation (Fig.2a). Echocardiographic parameters recorded included IVSd $(0.7 \mathrm{~cm})$, LVIDd $(3.4 \mathrm{~cm})$, LVPW $(0.7 \mathrm{~cm})$, IVSs $(1.0 \mathrm{~cm})$, LVIDs $(1.6$ $\mathrm{cm}), \mathrm{LVPW} \quad(0.8 \mathrm{~cm}), \mathrm{EDV}(48 \mathrm{ml}), \mathrm{ESV}(6.7 \mathrm{ml}), \mathrm{SV}$ (42 ml), IVS/ LVPW (0.94), EF ( $86.1 \%)$, FS (54.4\%), SI $\left(16.5 \mathrm{~mL} / \mathrm{m}^{2}\right)$, and LA/ AO (1.5 ) (Fig 2b). The dog was diagnosed to be having mitral and tricuspid regurgitation with normal systolic function. The dog was administered with enalapril $(0.5 \mathrm{mg} / \mathrm{kg}$ body weight bid PO) and frusemide ( $2 \mathrm{mg} / \mathrm{kg}$ bodyweight bid PO). Following treatment, the dog on second day showed improvement in clinical condition with reduction in ascites, cough and exercise intolerance. There was improvement in the appetite and the animal became active and alert by $6^{\text {th }}$ day of treatment. The owner was advised to give salt restricted diet and not to give exercise to the dog. The oral medication was continued and the dog was periodically evaluated.

After three months, the dog was brought to the hospital with complaint of not sleeping, coughs, and was dull, depressed, tired, and recumbent for most of the time. Blood pressure was $120 \mathrm{mmHg}$, cardiac murmur; exaggerated lung sound and odema of hind

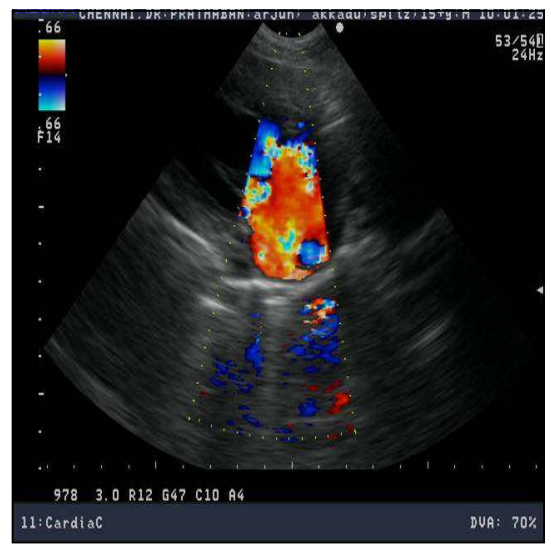

Fig-2a. Colour doppler echocardiography of the dog showing regurgitation 


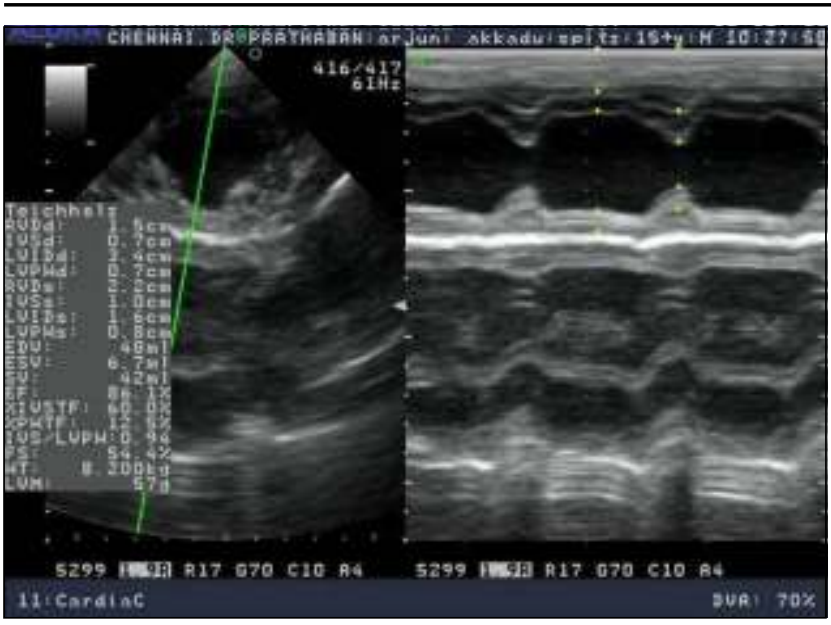

Fig-2b. M mode echocardiography of the dog

limbs were noticed. The dog was subjected to echocardiogram and the echocardiographic indices observed included IVSd $(0.6 \mathrm{~cm})$, LVIDd $(3.5 \mathrm{~cm})$, LVPW $(0.7$ $\mathrm{cm})$, IVSs $(1.0 \mathrm{~cm})$, LVIDs $(2.0 \mathrm{~cm})$, LVPW $(1.1 \mathrm{~cm})$, EDV (52ml), ESV(13 ml), SV(39ml), IVS/LVPW (0.87), EF (74.7\%), FS(42.6\%), SI $\left(32.5 \mathrm{~mL} / \mathrm{m}^{2}\right)$, and LA/ AO (1.72) (Fig 2c). The systolic index was more than $30 \mathrm{~mL} / \mathrm{m}^{2}$ indicative of myocardial dysfunction. The dog was administered with digoxin@0.005 mg $/ \mathrm{kg}$ body weight $\mathrm{PO}$ bid. The dog showed improvement in clinical signs like improvement in appetite and became active, ambulatory and able to move about for urination and defecation. FS and EF indices during the echocardiography taken in one month after start of digoxin therapy were $48 \%$ and $80 \%$. The owner was advised to continue with oral medication, restricted physical activities and salt restricted diet.

\section{Discussion}

Chronic valvular heart disease is a degenerative disorder of unknown cause affecting the endocardial and sub endocardial portion of the valve leaflets [4]. In the present case, clinical signs noticed were inappetance, dyspnoea, cough, exercise intolerance, tachycardia, and ascites. Respiratory distress, cough, weakness, pleural effusion, ascites, pulmonary oedema, orthopnoea, cachexia and murmur might be noticed in dogs with valvular insufficiency [3]. Syncope, arrhythmia and fibrillation might be noticed in some cases. The clinical signs noticed in the present study concurred with the reports of the above authors. Dogs with a cough of non-cardiac origin had a significantly lower VHS (mean +/- SD, 11 $+/-0.9)$ compared with those of dogs with a cough of cardiac or mixed origin $(12.8+/-1$ and $12.9+/-0.9$, respectively) [5]. Similar changes were noticed in the present study. Electrocardiographic changes in dogs with mitral valve insufficiency ranged from normal to marked abnormalities in rate, rhythm or configuration of complexes and those of tricuspid insufficiency included evidences of right atrial and right ventricular enlargement, arrhythmia, ventricular premature complexes and atrial fibrillation [6]. In the present case sinus arrhythmia was present.

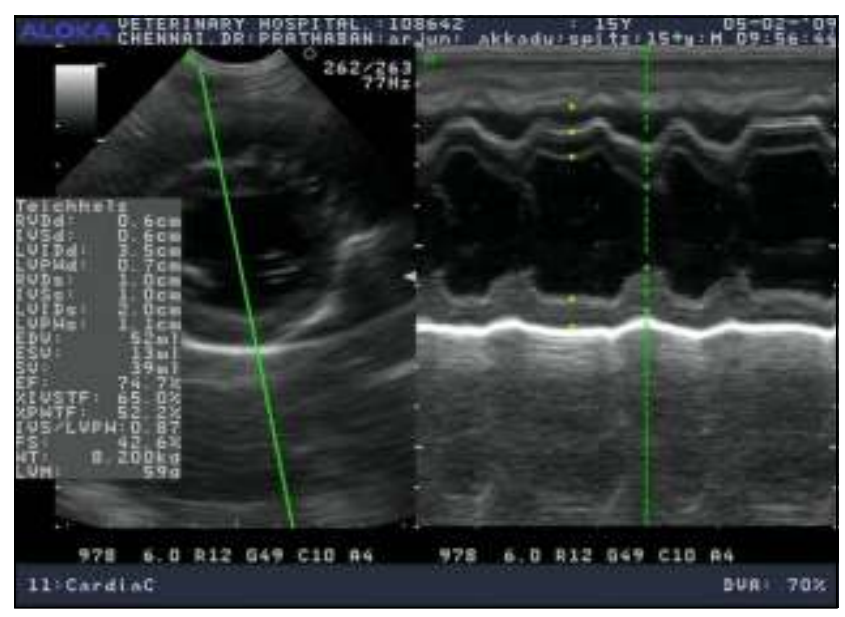

Fig-2c. M mode echocardiography of the dog taken after 3 months showing reduced $\mathrm{FS}$ and $\mathrm{EF}$

Increased LA / Ao ratio, and exaggerated motion of septum and free wall were noticed in dogs with mitral insufficiency. The increase in LA/ Ao ratio suggested atrial dilatation [1]. In the present study the $\mathrm{La} / \mathrm{Ao}$ ration was more than 1.5 at all times. In the present study systolic index (ESV/BSA) and fractional shortening were less than $30 \mathrm{ml} / \mathrm{m}^{2}$ and above $50 \%$ respectively. Dogs with severe myocardial failure, mild myocardial impairment, moderately reduced myocardial contractility and normal myocardial contractility had systolic index of $<100 \mathrm{ml} / \mathrm{m}^{2}, 34-70$ $\mathrm{ml} / \mathrm{m}^{2}, 70-100 \mathrm{ml} / \mathrm{m}^{2}$, and $<30 \mathrm{ml} / \mathrm{m}^{2}$ respectively [7]. This explained that dog under present study had no myocardial dysfunction. Fractional shortening in dogs with mitral insufficiency without myocardial dysfunction, mild to moderately impaired myocardial contractility and severe myocardial failure were < $50 \%, 30-45 \%$ and $<33 \%$ respectively [1]. Systolic myocardial function was preserved in dogs with mitral regurgitation until late in the course of the disorder, because the left ventricle was able to unload a portion of its stroke volume into left atrium early in systole and reduce its wall stress [7]. This offered explanation for the fractional shortening to be within the normal range in dogs with mitral valve insufficiency. In the present case at the time of presentation, the FS and EF were above the normal and SI was less than $30 \mathrm{ml} / \mathrm{m} 2$. Hence the treatment included only enalapril and frusemide. As the SI indicative of myocardial failure increased and the clinical signs worsened, the dog was administered with digoxin. Use of diuretics, ACE inhibitors, direct vasodilators, digoxin and pimobendon, pulmonary medications and dietary measures had been advocated for the valvular diseases in dogs [8]. In the present case, digoxin was used because of nonavailability of pimobendon in the market. This article emphasized that digoxin need not be used in cases of valvular regurgitation until the animal developed systolic failure.

\section{Acknowledgements}

The authors are thankful to the Dean, Madras Veterinary College, Chennai for providing necessary facilities for the study. 


\section{References}

1. Boon, J.A. (2006). Manual of Veterinary Echocardiography. Blackwell Publishing. Professional, Ames, Iowa, USA.

2. Chetboul, V. and Tissier, R. (2012) Echocardiographic assessment of canine degenerative mitral valve disease. $J$. Vet. Cardiol., 14:127-48.

3. Olsen, L.H., Haggstrom, J and Petersen, H.D. (2010). Acquired Valvular heart disease. In Ettinger, S.J. and Feldman, E, C. (ed): Textbook of Veterinary Internal Medicine, $7^{\text {th }}$ edition. Philadelphia, W.B. Saunders, pp. 12991319.

4. de Madron, E., King,J.N., Strehlau,G. and White, R.V. (2011) Survival and echocardiographic data in dogs with congestive heart failure caused by mitral valve disease and treated by multiple drugs: A retrospective study of 21 cases. Can. Vet.J., 52:1219-1225.

5. Guglielmini, C., Diana, A., Pietra, M., Di Tommaso, M. and Cipone, M. (2009). Use of the vertebral heart score in coughing dogs with chronic degenerative mitral valve disease. J Vet Med Sci., 71:9-13.

6. Miller, M.S and Tilley, L.P. (1995). Manual of canine and feline cardiology. $2^{\text {nd }}$ edition. W.B. Saunders Company, Philadelphia.

7. Kittleson, M.D and Kienle, R.D. (1998). Small Animal Cardiovascular Medicine, Mosby Inc, St. Louis.

8. Atkins, C.E., Bonagura, J.D, and Ettinger, S. (2009). Guidelines for the diagnosis and treatment of canine chronic valvular heart disease. J. Vet. Int. Med., 23:1142-1150.

$* * * * * * * *$ 